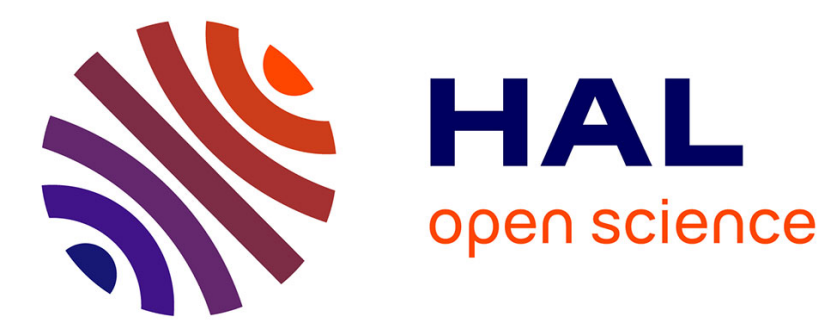

\title{
Determining soil permeability from pressuremeter tests
}

\author{
Damien Rangeard, Pierre-Yves Hicher, R. Zentar
}

\section{To cite this version:}

Damien Rangeard, Pierre-Yves Hicher, R. Zentar. Determining soil permeability from pressuremeter tests. International Journal for Numerical and Analytical Methods in Geomechanics, 2003, 27 (1), pp.1-24. 10.1002/nag.258 . hal-01006735

\section{HAL Id: hal-01006735 \\ https://hal.science/hal-01006735}

Submitted on 7 Feb 2017

HAL is a multi-disciplinary open access archive for the deposit and dissemination of scientific research documents, whether they are published or not. The documents may come from teaching and research institutions in France or abroad, or from public or private research centers.
L'archive ouverte pluridisciplinaire HAL, est destinée au dépôt et à la diffusion de documents scientifiques de niveau recherche, publiés ou non, émanant des établissements d'enseignement et de recherche français ou étrangers, des laboratoires publics ou privés. 


\title{
Determining soil permeability from pressuremeter tests
}

\author{
D. Rangeard ${ }^{1}$, P. Y. Hicher ${ }^{1}$ and R. Zentar ${ }^{2}$ \\ 1 - Laboratoire de Génie-Civil de Nantes Saint-Nazaire, Ecole Centrale de Nantes, France \\ 2 -Department of Civil Engineering, Glasgow University, Scotland
}

This paper presents a methodology for identifying soil permeability from pressuremeter test. On the first part we present a numerical analysis of the permeability effects on the test results. We demonstrate that different drainage conditions arise during test, as a function of the loading rate and the soil permeability. We also studied the pore pressure dissipation during strain holding stages. Based on this analysis of these tests, we propose a general procedure to identify simultaneously mechanical parameters and permeability from pressuremeter tests with strain holding test stages. This procedure was applied on tests performed on natural Saint Herblain clay. An apparatus called pressio triax was developed for this purpose. The values of the mechanical parameters as well as of the permeability value were found to agree very well with the values of the same parameters obtained from conventional laboratory tests.

\section{INTRODUCTION}

The particular test known as pressuremeter test was first developed by Menard and his coworker in 1955 [1]. During the early 1960s great efforts were made to improve the equipment and to insure better reliability of the tests. In order to minimize disturbance in the soil, a selfboring pressuremeter test was developed independently, at the 'Laboratoire Central des Ponts et Chaussées [2] and at Cambridge University [3] in 1972'. This test consists of expanding a cylindrical cavity in an infinite medium. The pressuremeter probe is inflated at a controlled strain rate while the pressure and the volume change of the cavity are measured. This kind of test is well known in geotechnical engineering and considerable research work has been done on this problem (see for example the pioneer studies of Gibson and Anderson [4], Palmer [5]).

Due to the non-homogeneity of the stress field generated in soil around the pressuremeter probe, partial drainage can occur which, depending on the rate of loading and/or the permeability of the soil, induces changes of the mechanical soil characteristics. A number of authors have shown that the strain rate affects the undrained shear strength derived from pressuremeter tests [6-9]. The consolidation of soil during a pressuremeter test was first studied by Randolph and Wroth [10], who used a pressuremeter with pore pressure measurement to 
determine soil permeability, assuming an elastic behaviour of the soil skeleton. Fiovarante et al. [11] showed that this assumption regarding the soil behaviour could have a significant influence on the derived permeability parameter. In order to study this kind of problem in tightly controlled conditions, new equipment called pressio-triax was developed [12]. This apparatus allows us to simulate a self-boring presssuremeter with pore water pressure measurement at the cavity wall. The equipment is presented in detail in Section 6.

In the first part of this paper, we analyse pressuremeter and pressio-triax tests with particular attention paid to the pore pressure development during these tests.

We then present a numerical analysis of a strain holding test stage during a pressio-triax test. Based on this analysis we propose a method for determining the soil radial permeability and the drainage conditions during the cavity expansion. This procedure is then applied to pressio-triax tests with pore pressure measurement realized on Saint-Herblain soft clay.

\section{NUMERICAL STUDY OF PRESSUREMETER TEST}

\subsection{Geometry and boundary conditions}

Numerical simulations of pressuremeter tests as well as of pressio-triax tests were performed by use of a finite elements code CESAR-LCPC. For the pressio-triax tests simulations, we took into account the geometry of the specimen, where the ratio of the outer diameter $(2 b)$ to inner diameter $(2 a)$ is about 5.38. For in situ pressuremeter test simulations in soft clays with typical parameters of Saint-Herblain clay, a typical value of the ratio $(b / a)$ equal to 30 is sufficient to model the condition of infinite medium [13]. However, for sands or stiff clays this ratio has to be higher as reported by Bahar [14].

Considering the plane strain conditions, this study modellizes a unit height of soil. In the horizontal direction, a ratio $b / a$ equal to 5.38 is used for pressio-triax tests and a ratio equal to 30 for pressuremeter tests.

For the pressio-triax test the mesh is composed of 27 elements with 123 nodes, and for the pressuremeter test the mesh is composed of 58 elements with 237 nodes. For both pressuremeter and pressio-triax test simulations, the elements are isoparametric with 8 integration points.

In terms of boundary conditions, all vertical displacement on sides A and B was prevented, whereas horizontal displacements could develop freely.

For the pressio-triax test, the cell pressure is applied on side $\mathrm{C}$ and the pressure in the minipressuremeter probe is applied on side D (Figure 1).

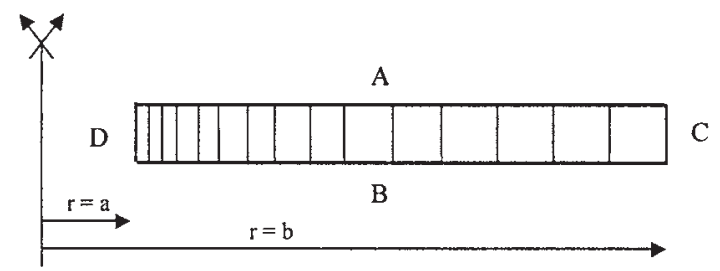

Figure 1. Finite element geometry. 
For the pressuremeter test, on the outer boundary condition (side C), a constant pressure equal to the horizontal stress in the ground is applied. On the inner boundary (side D) the pressure imposed by the pressuremeter probe is applied.

The loading process for both tests is a continuous loading process with a stress rate of $20 \mathrm{kPa} / \mathrm{min}$. This rate corresponds to the usual rate used to perform experimental tests.

We modellized a unit height of soil situated in the centre of the pressuremeter probe. So, using the symmetry of the probe, no water exchange was allowed to pass through the four faces in both pressuremeter and pressio-triax conditions.

\subsection{Constitutive model and initial state of stress}

The constitutive model used in this study to model the mechanical behaviour of the soil is the Modified Cam-Clay Model as described by Roscoe and Burland [15]. However, an isotropic linear elasticity is assumed here. The yield function as well as the model parameters are briefly summarized in Figure 2, where $M$ is the slope of the critical state line in the $\left(q-p^{\prime}\right)$ plane; $\beta=(\lambda-\kappa)$, where $\lambda$ and $\kappa$ are respectively, the slope of the virgin consolidation and of the swelling line in the $\left(e-\ln p^{\prime}\right)$ diagram, $e$ the void ratio and $p_{c 0}^{\prime}$ the preconsolidation pressure. The elastic behaviour is linear and isotropic with a constant value of Poisson's ratio $v$ and Young's modulus $E$.

At the studied depth (between 7 and $8 \mathrm{~m}$ ), the preconsolidation pressure is about $50 \mathrm{kPa}$ and the initial state of stress is as defined in Table I, corresponding to an overconsolidation ratio OCR of 1.82. This initial state of stress was determined by considering the profile of the unit weight of the soil and by assuming a water table at the depth of $1 \mathrm{~m}$ below the ground surface. The initial effective vertical stress is therefore equal to $32.5 \mathrm{kPa}$ and the initial pore water pressure is equal to $65 \mathrm{kPa}$. Assuming that the coefficient earth pressure at rest $K_{0}$ is equal to 0.52 , the effective radial stress is then equal to $17 \mathrm{kPa}$.

For numerical simulations, the soil was assumed to be saturated and the permeability was assumed to be isotropic.

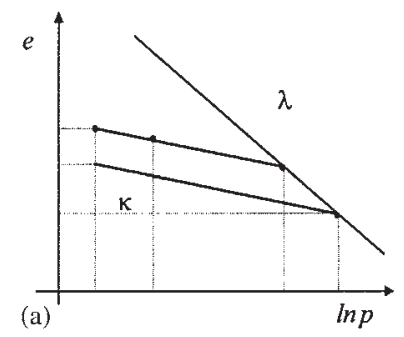

(b) 0

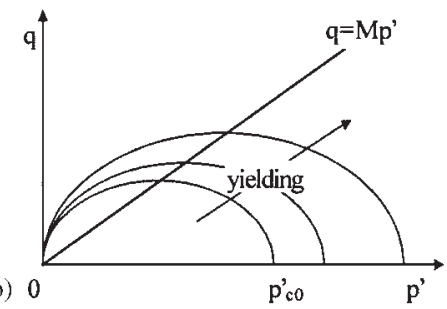

Figure 2. Modified Cam Clay model representation.

Table I. Modified Cam Clay parameters used in this study.

\begin{tabular}{lccccccccc}
\hline $\begin{array}{l}G \\
(\mathrm{kPa})\end{array}$ & $v$ & $\beta$ & $M$ & $e_{0}$ & $\begin{array}{c}p_{c 0}^{\prime} \\
(\mathrm{kPa})\end{array}$ & $\begin{array}{c}k \\
(\mathrm{~m} / \mathrm{s})\end{array}$ & $\sigma_{r 0}^{\prime}$ & $\begin{array}{c}\sigma_{v 0}^{\prime} \\
(\mathrm{kPa})\end{array}$ & $u_{0}$ \\
\hline 899 & 0.3 & 1.15 & 1.2 & 4.0 & 51 & $1 \times 10^{-9}$ & 17 & 32.5 & 65 \\
\hline
\end{tabular}


A typical set of modified Cam-Clay parameters and the initial state of stress are presented in Table I. These parameters are typical of Saint-Herblain clay at the depth chosen for our study.

\subsection{Typical results of pressuremeter test and pressio-triax test simulations}

Figure 3 presents typical results in terms of applied pressure and of pore water pressure generated at the cavity wall as function of the strains at the cavity wall for a pressuremeter test (Figure 3(a)) and for a pressio-triax test (Figure 3(b)).

As shown in Figure 3, for pressure less than $107 \mathrm{kPa}$ (corresponding to a cavity strain of 1\%) the behaviour of the soil is purely elastic. The pore water pressure remains constant, and the slope of the stress-strain curve is controlled by the value of the shear modulus $G$. The stressstrain curves are similar in the elastic zone for both pressuremeter and pressio-triax tests. For higher applied pressure, yielding is initiated at the cavity wall and a linear relationship between stresses and strains is no longer apparent. At the same time, the pore water pressure increases.

Figure 4 presents the total stress and pore water pressure distributions along the radius for a cavity strain level of 0.5 and $10 \%$ for both pressuremeter and pressio-triax simulations. In these figures, the stresses are normalized by the initial horizontal total stress $\sigma_{r 0}$. For $\delta_{a}\left(\delta_{a}=d_{a} / a, d_{a}\right.$ is the cavity wall displacement, $a$ the initial cavity radius) equal to $0.5 \%$ (Figure 4(a) and 4 (b)) we obtain typical stress distributions during the elastic phase $\left(0<\delta_{a}<1 \%\right)$. During this phase, while the radial stress increases, the circumferential stress decreases at the same rate. The vertical stress and the pore water pressure remain constant. Stress distributions for the pressuremeter and the pressio-triax tests are the same at this strain level.

In Figures 4(c) and 4(d) stress distributions are shown for a cavity strain level of $10 \%$, when the soil around the cavity deforms plastically. For this value of the cavity strain, we can see in Figure 3 that the pressure applied at the cavity wall is found to be equal to $150 \mathrm{kPa}$ for the pressuremeter test, and equal to $143 \mathrm{kPa}$ for the pressio-triax test. This difference appears in the values of the radial stress at the cavity wall $(r / a=1)$. At this strain level, the plastic zone expands from the cavity wall to the same value of the radius (here for $r / a$ equals to 3.2) for both pressuremeter and pressio-triax tests.

In the plastic region, all the stress components decrease along the radius starting from the cavity wall. The pore pressure has the same evolution as the radial stress. More precisely, the effective stress distributions along a radius clearly show that the effective radial $\left(\sigma_{r}-u\right)$ and effective orthoradial $\left(\sigma_{\theta}-u\right)$ stresses are constant in the plastic zone (Figure 5).
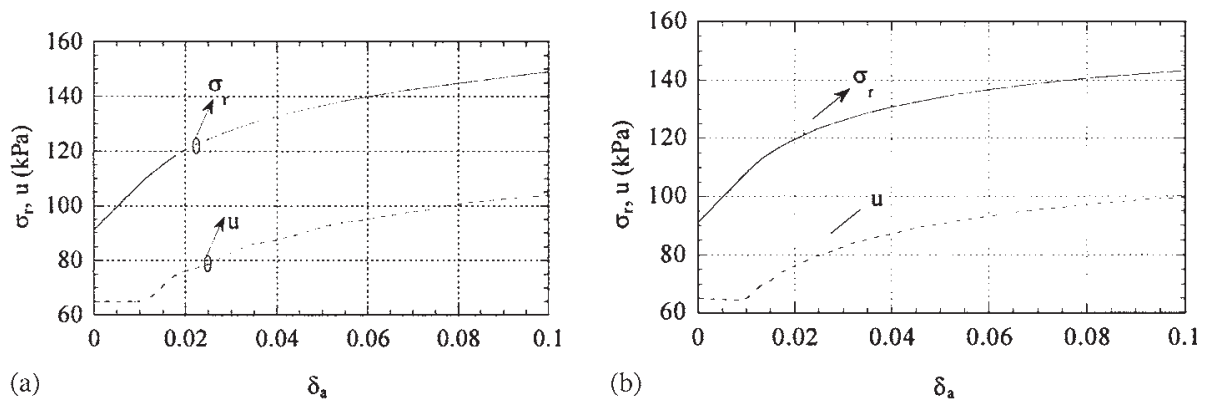

Figure 3. Numerical simulation of (a) pressuremeter test; (b) and pressio triax test. 

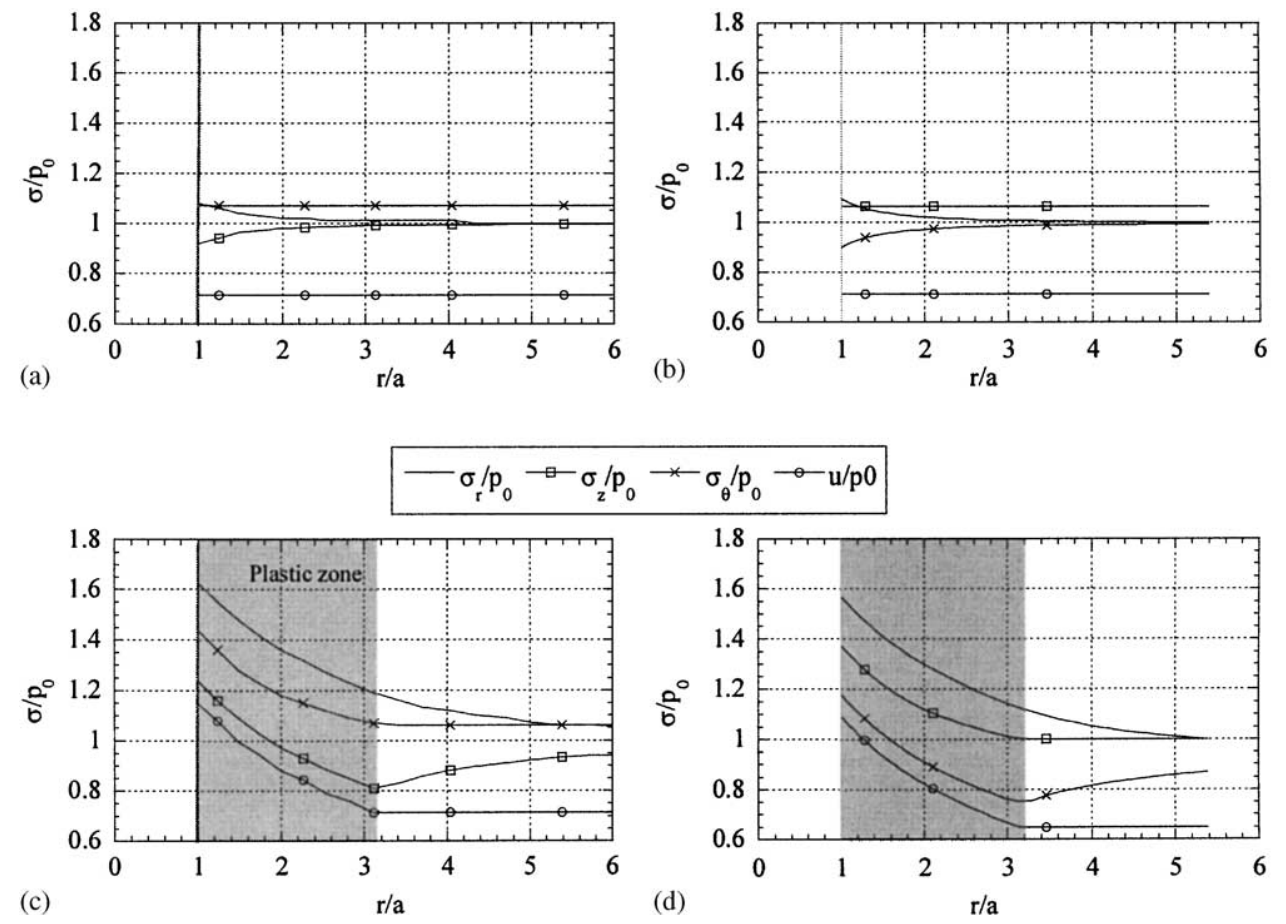

Figure 4. Stress distribution along the radius for $\delta_{a}=0.5 \%$ for pressuremeter test (a) and pressio triax (b); for $\delta_{a}=10 \%$ for pressuremeter test (c) and pressio triax (d).

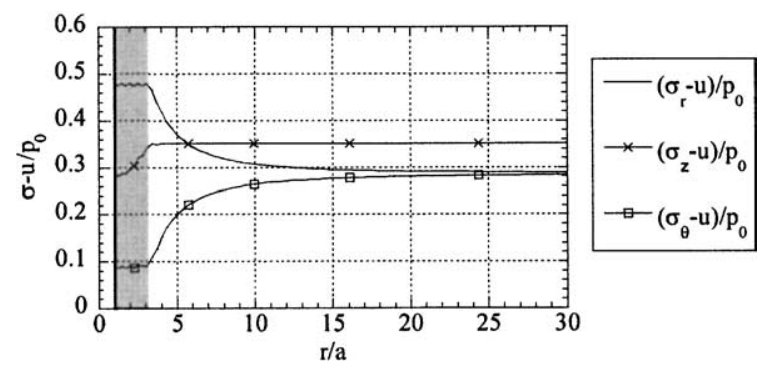

Figure 5. Effective stress distributions for $\delta_{a}=10 \%$.

\section{PERMEABILITY EFFECT ON THE TEST RESULTS}

\subsection{Permeability effect on pressuremeter curves}

In order to study the effect that the soil permeability has on the stress-strain curve during a pressuremeter and a pressio-triax test, numerical simulations were made for various values of permeability. Other soil parameters were maintained constant and equal to the values presented in Table I. The stress rate used for these simulations was $20 \mathrm{kPa} / \mathrm{min}$. As shown in Figure 6 , for soil with small permeability $\left(k<10^{7} \mathrm{~m} / \mathrm{s}\right)$, the soil behaviour is undrained. For high 

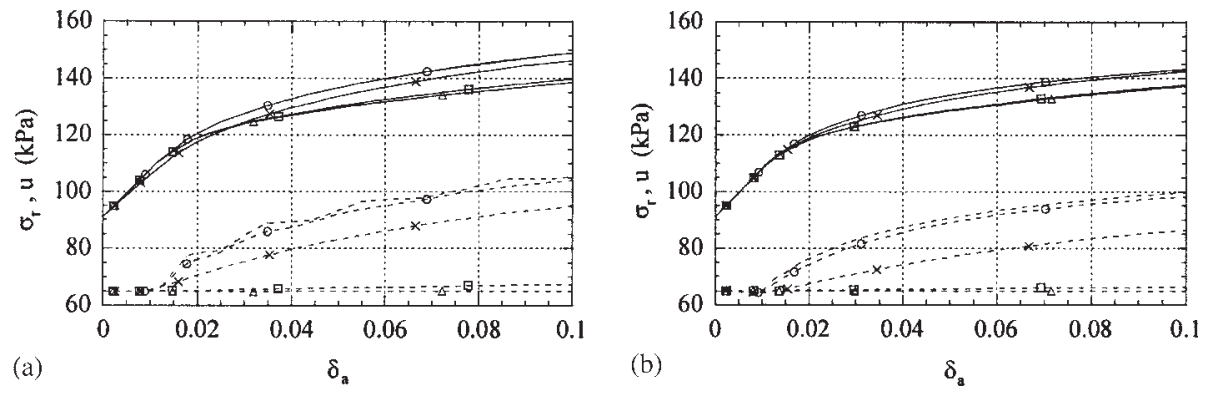

$$
\begin{array}{rl|}
{ }_{\mathrm{k}}=10^{-9} \mathrm{~m} / \mathrm{s} & { }^{*} \mathrm{k}=10^{-5} \mathrm{~m} / \mathrm{s} \rightarrow{ }^{-} \mathrm{k}=10^{-1} \mathrm{~m} / \mathrm{s} \\
\mathrm{k}=10^{-7} \mathrm{~m} / \mathrm{s} & \rightarrow \mathrm{k}=10^{-3} \mathrm{~m} / \mathrm{s} \\
\hline
\end{array}
$$

Figure 6. Permeability effect on stress strain curves for pressuremeter tests (a) and pressio triax tests (b).
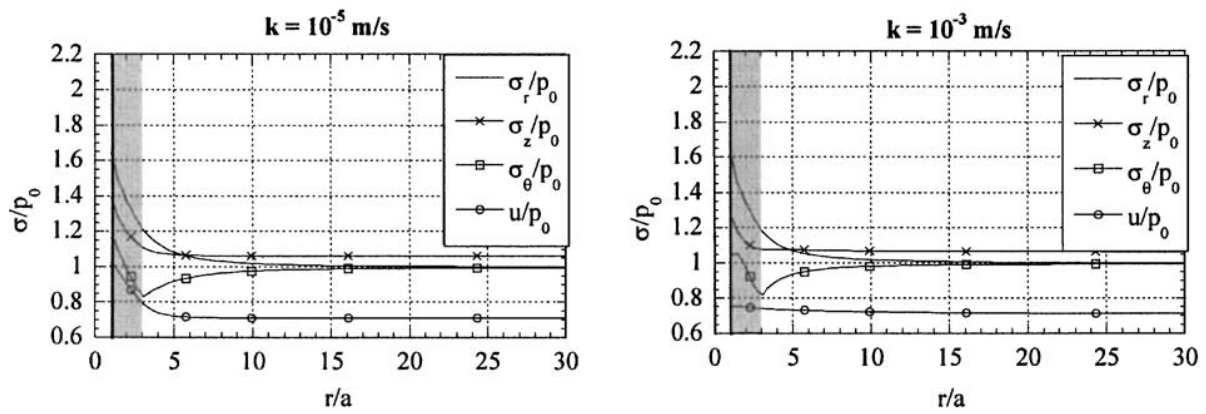

Figure 7. Stress distribution along a radius for an applied pressure of $60 \mathrm{kPa}$ for different permeability.

permeability $\left(k>10^{3} \mathrm{~m} / \mathrm{s}\right)$ the soil behaviour is drained. For intermediate value of permeability $\left(10^{7}<k<10^{3} \mathrm{~m} / \mathrm{s}\right)$ the behaviour is partly drained. This result is verified for both pressuremeter and pressio-triax tests.

\subsection{Permeability effect on stress distribution}

In Figure 7, the stresses corresponding to an applied pressure of $60 \mathrm{kPa}$ in the probe are reported as a function of the radius for different values of permeability.

In the cases at hand, we can assume that the cavity expansion occurs in undrained conditions for $k<10^{5} \mathrm{~m} / \mathrm{s}$. For the other cases $\left(k>10^{5} \mathrm{~m} / \mathrm{s}\right)$ the calculated $\Delta u$ at the cavity wall is smaller. In particular, for $k=10^{3} \mathrm{~m} / \mathrm{s}$, the pore water pressure is not influenced by the loading. The test occurs in fully drained conditions.

In Figure 8, we present the effective radial stress $\left(\sigma_{r}-u\right)$, for different values of permeability, function of the radius. We can see that, for permeability smaller than $10^{5} \mathrm{~m} / \mathrm{s}$, the value of the effective stress is constant in the plastic zone. For higher values of the permeability, the radial effective stress decreases regularly in the plastic zone. 


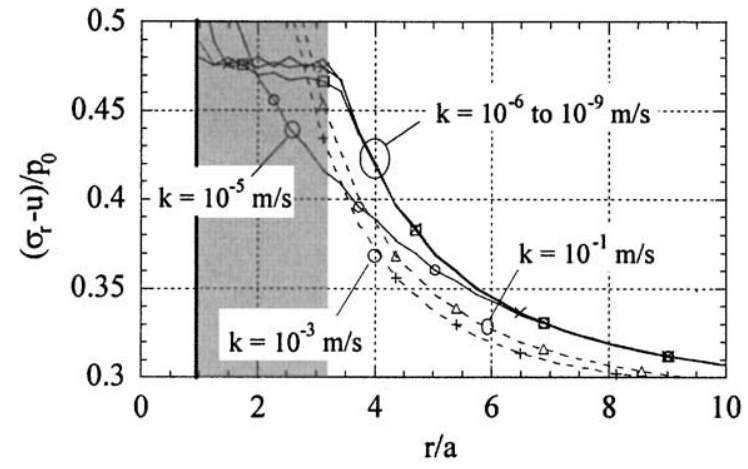

Figure 8. Variation of effective stress $\left(\begin{array}{lll}\sigma_{r} & u\end{array}\right) / p_{0}$ along a radius for soil permeability varying from $10^{-1}$ to $10^{-9} \mathrm{~m} / \mathrm{s}$.
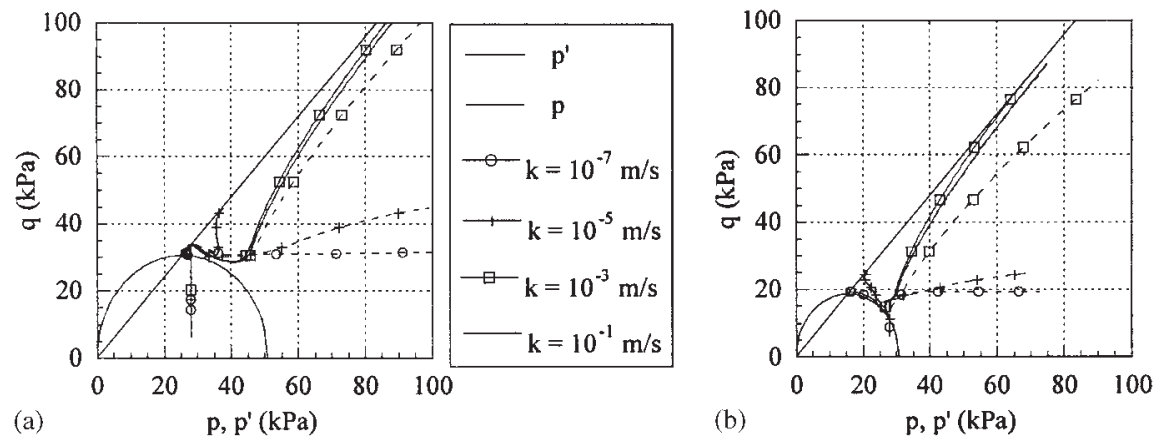

Figure 9. Permeability effect on pressuremeter stress path: (a) $p_{c 0}^{\prime}=51 \mathrm{kPa}$; (b) $p_{c 0}^{\prime}=31 \mathrm{kPa}$.

If we analyse the stress path obtained for different values of permeability at the cavity wall (for $r=a$ in Figure 9(a), we can see that for values smaller than $10^{5} \mathrm{~m} / \mathrm{s}$, the effective stress path meets up with the critical state line near the yield surface, and the total stress path is characterized by a constant value of the deviator stress $q$. This is explained by an initial value of the overconsolidation ratio of 1.82 (near 2).

For higher values of permeability, the effective stress path meets up with the critical state line for a higher value of the deviatoric stress. This value corresponds to the increase of the effective stress observed at the cavity wall for $k>10^{5} \mathrm{~m} / \mathrm{s}$.

The stress path obtained for an overconsolidated ratio of $1.1\left(p_{c 0}^{\prime}=31 \mathrm{kPa} ; p_{0}^{\prime}=28 \mathrm{kPa}\right)$ is presented in Figure 9(b). We can draw the same conclusions here as for the previous case.

In Figure 10, the stress paths corresponding to different overconsolidation ratio (1, 2 and 4) are presented. For an overconsolidation ratio of 4, as for an overconsolidation ratio of 1 or 2 , the stress path meets up with the critical state line near the initial yield surface.

\subsection{Classical interpretation of the pressuremeter test}

We analyse here the permeability effect on the results derived from a classical method of interpretation, presented by Gibson and Anderson [4]. These authors describe the analysis of 


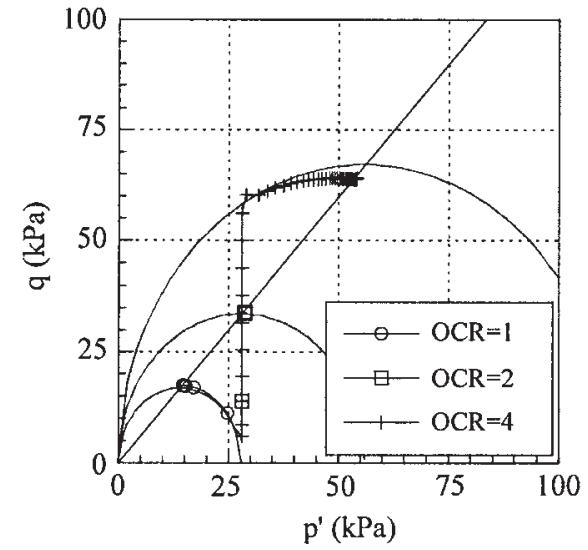

Figure 10. Stress paths obtained for overconsolidation ratio of 1,2 and 4 for permeability equal to $1 \times 10^{-9} \mathrm{~m} / \mathrm{s}$.
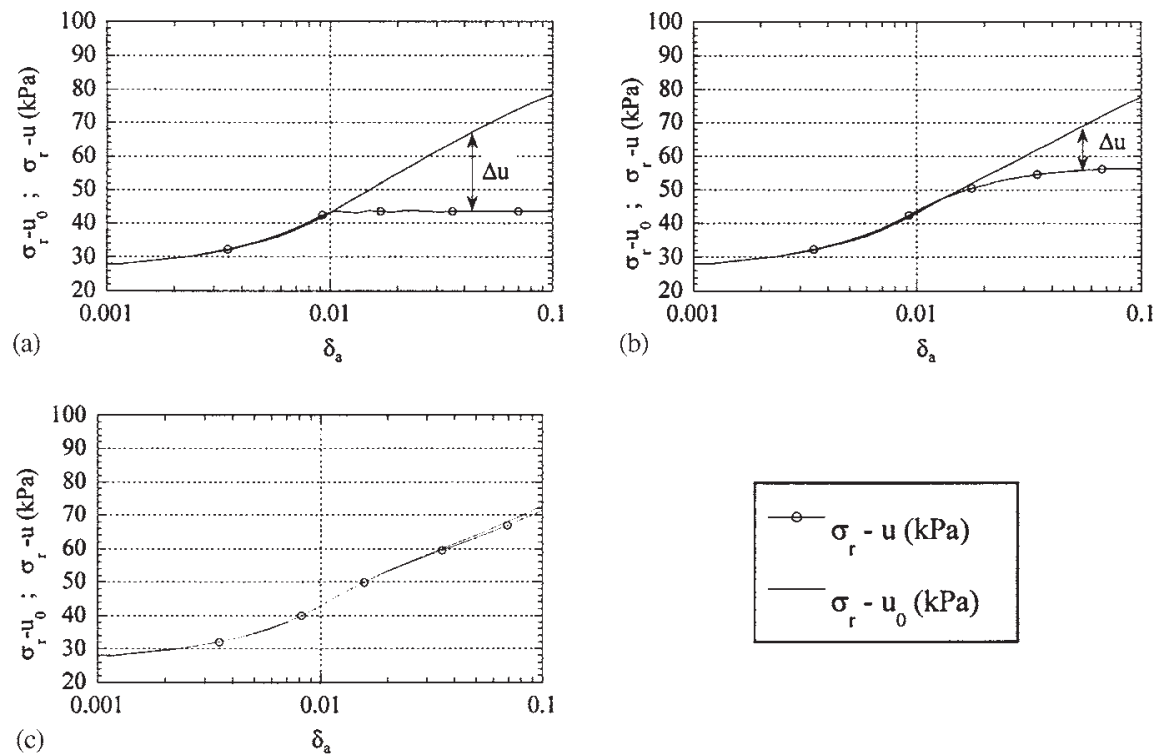

Figure 11. Pressuremeter curves in a $p \ln \left(\delta_{a}\right)$ diagram for different permeabilities. (a) $k=$ $10^{-7} \mathrm{~m} / \mathrm{s}$; (b) $k=10^{-5} \mathrm{~m} / \mathrm{s}$; (c) $k=10^{-3} \mathrm{~m} / \mathrm{s}$.

undrained expansion of a cylindrical pressuremeter in clay. Assuming an elastic, perfectly plastic model, they have shown that the undrained shear strength of the soil $c_{\mathrm{u}}$ could be defined from the slope of the pressuremeter curve in a $p-\ln \left(\delta_{a}\right)$ diagram.

In Figure 11, pressuremeter curves for three different soil permeabilities are plotted in the semi-logarithmic diagram $\left(\sigma_{r}-\log \left(\delta_{a}\right)\right)$. In the case of low permeability $\left(k=10^{7} \mathrm{~m} / \mathrm{s}\right.$, Figure 11(a)), the effective radial stress is constant in the plastic region. The difference between the two curves $\left(\sigma_{r}-u\right.$ and $\left.\sigma_{r}-u_{0}\right)$ corresponds to the excess pore water pressure. For $k=$ 


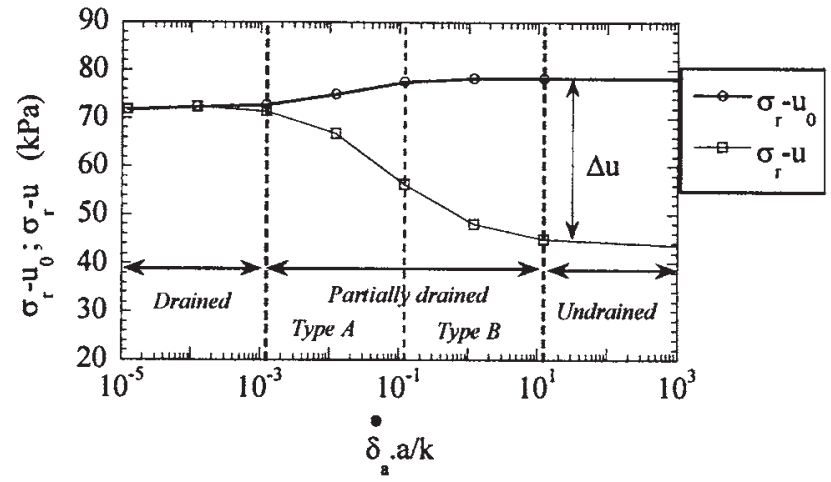

Figure 12. Evolution of the total stress $\sigma_{r} \quad u_{0}$ and of effective stress $\sigma_{r} \quad u$ as a function of the variable $\dot{\delta}_{a} / k a$.

$10{ }^{5} \mathrm{~m} / \mathrm{s}$ (Figure 11(b)), the evolution of the total stress $\left(\sigma_{r}-u\right)$ corresponds to the one obtained with $k=10^{7} \mathrm{~m} / \mathrm{s}$. However, the excess pore pressure is smaller than the one observed for the low permeability test. For a drained test $\left(k>10^{3} \mathrm{~m} / \mathrm{s}\right)$, the total and the effective curves are superposed (no excess pore pressure). In this case, the slope of the straight line cannot be defined as undrained shear strength. The $c_{\mathrm{u}}$ values derived from these curves according to the method of Gibson and Anderson are 17.5, 17 and $13 \mathrm{kPa}$ for permeabilities of $10^{7} \mathrm{~m} / \mathrm{s}, 10^{5}$ $\mathrm{m} / \mathrm{s}$ and $10^{3} \mathrm{~m} / \mathrm{s}$. The permeability factor influences the value of $c_{\mathrm{u}}$ derived from this method by $25 \%$.

To interpret this conclusion in terms of strain rate, we can express the initial strain rate at the cavity wall as

$$
\dot{\delta}_{a}=\frac{\Delta p / \Delta t}{2 G}
$$

where $\Delta p / \Delta t$ is the probe inflating rate and $G$ the shear modulus.

The strain rate $\dot{\delta}_{a}$, can be compared with the same ratio $k / a$.

We can represent the evolution of the total stress $\left(\sigma_{r}-u_{0}\right)$ and of the effective stress $\left(\sigma_{r}-u\right)$ at the cavity wall as a function of the non-dimensional variable $\dot{\delta}_{a} a / k$ (Figure 12). We can then observe four different types of behaviour during a pressuremeter test: fully drained, partially drained (types A and B) and undrained. The partially drained behaviour can be divided into two categories. The partially drained type B behaviour is an 'undrained' behaviour if we consider the total stress, but the pore pressure evolution is influenced by the drainage. As for the partially drained type A behaviour, the total pressure and the pore pressure are influenced by the drainage.

\section{NUMERICAL STUDY OF STRAIN HOLDING TESTS}

Given the results obtained above, we can consider that the pressio-triax test reproduces correctly the pressuremeter test. In this part, therefore, a strain-holding test during a pressio-triax test is modellized and the results will then be compared to experimental pressio-triax results. 
Since the Cam-Clay model does not take into account the viscous behaviour of the clay, the stress relaxation which occurred during strain holding tests could not be reproduced. However, we assumed that the stress relaxation did not affect the pore pressure evolution during strain holding phases. This assumption was based on results obtained in triaxial tests which showed that, during a stress relaxation test performed in undrained conditions, no pore pressure evolution was observed inside the clay samples. Therefore, the pore pressure evolution in strain holding stages during pressio-triax tests can be considered as dependent only on the permeability of the specimen. In future work, this assumption will be dismissed and the CamClay model will be replaced by a viscoplastic model.

The geometry considered in this analysis is the one described in Section 1.1 with a $b / a$ ratio of 5.38. The material characteristics are those defined in Table I. The cavity strain at the beginning of the relaxation stage is equal to $4 \%$.

The pore water pressure evolution along the radius (Figure 13(a)) at different stages, shows a pressure stabilization at a time equal to $4.7 \times 10^{6} \mathrm{~s}$. More precisely, the pore water pressure evolution function of time for different values of the radius (at the cavity wall, $r=a$; in the soil, at the probe, $r=2 a$; at the outer boundary, $r=b$ ) is shown in Figure 13(b). This figure illustrates the pore pressure redistribution in space and time. Near the pressuremeter probe $(r=a)$, the excess pore pressure decays quickly with time. At the outer boundary $(r=b)$, the pore pressure increases until stabilization (obtained theoretically for an infinite time) occurs.

In order to analyse the permeability effect on the strain holding tests, several simulations with different values of the radial permeability were performed. Figure 14 shows the normalized
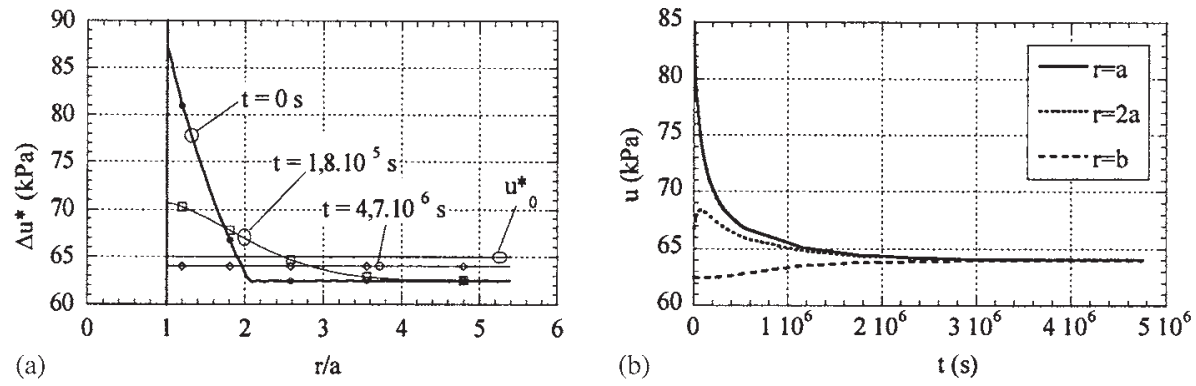

Figure 13. Pore water pressure distribution along a radius for different time (a); evolution with time for different (b).

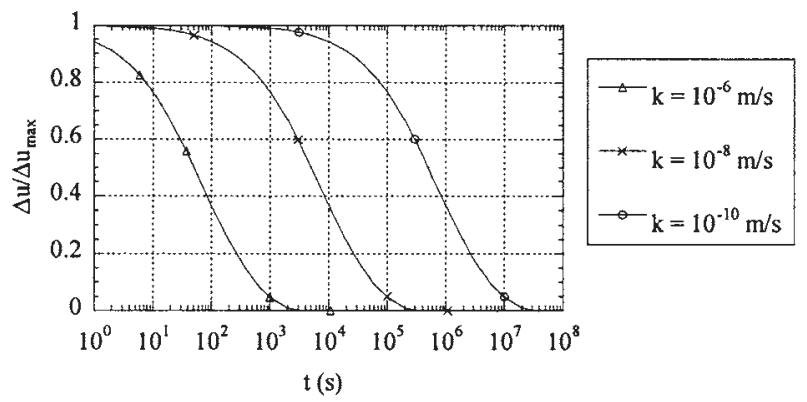

Figure 14. Permeability effect on pore pressure dissipation curves $\left(\mathrm{OCR}=2, \delta_{a}=4 \%\right)$. 
excess pore water pressure dissipation (for comparison purposes, the pore water pressure at different times was normalized according to the value of the pore pressure increase, $\Delta u_{\max }$, at the beginning of the strain holding test). We can deduce a direct relationship between the soil permeability and the excess pore water pressure dissipation rate. The time for total dissipation is multiplied by ten if the permeability is divided by ten.

\subsection{Cavity wall deformation and overconsolidation ratio effect on the pore pressure dissipation curves}

As shown in Figure 15, the overconsolidation ratio affects the pressuremeter curve and the pore pressure curve during cavity expansion. At the beginning of the strain holding test stage (here for $\delta_{a}=4 \%$ ), the generated pore pressure changes from 94.3 to $69.5 \mathrm{kPa}$ when the over-consolidation ratio changes from 1 to 4 . In the following (Figure 16), the pore pressure is normalized by the maximum value reached just before starting the strain holding test stage, so that we can compare the pore pressure dissipation during the strain holding stage for different cases.

In order to identify all the parameters which affect the pore pressure dissipation curve, we examined here the influence of the overconsolidation ratio (OCR), the cavity strain level and other model parameters $(M, \beta$ and $G)$ (Figures 16(a)-16(e)).

We can see from these figures that the dissipation curve is strongly influenced by the overconsolidation ratio and by the initial cavity strain level. For example, the time for $50 \%$ dissipation changes from $2 \times 10^{4}$ to $8 \times 10^{2} \mathrm{~s}$ when the overconsolidation ratio changes from 1 to 4 in Figure 16(a). The effect of the mechanical parameters $(M, \beta$ and $G)$ is less marked, nevertheless we should not neglect it completely in the interpretation of the strain holding test, specially in the case of $M$.

Knowing that the maximum excess pore pressure reached at the beginning of the strain holding test affects the time of dissipation, we present the time for $50 \%$ dissipation $\left(T_{50}\right)$ as a function of the maximum excess pore pressure for different overconsolidation ratios (Figure 17). No unique relation can be found between $T_{50}$ and the generated pore pressure at the beginning of the holding test.

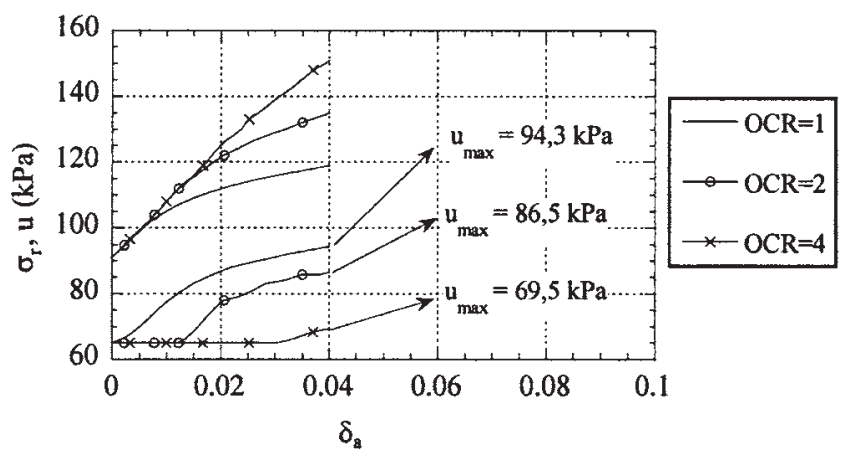

Figure 15. Effect of overconsolidation ratio on pressuremeter and pore pressure curve before strain holding test. 

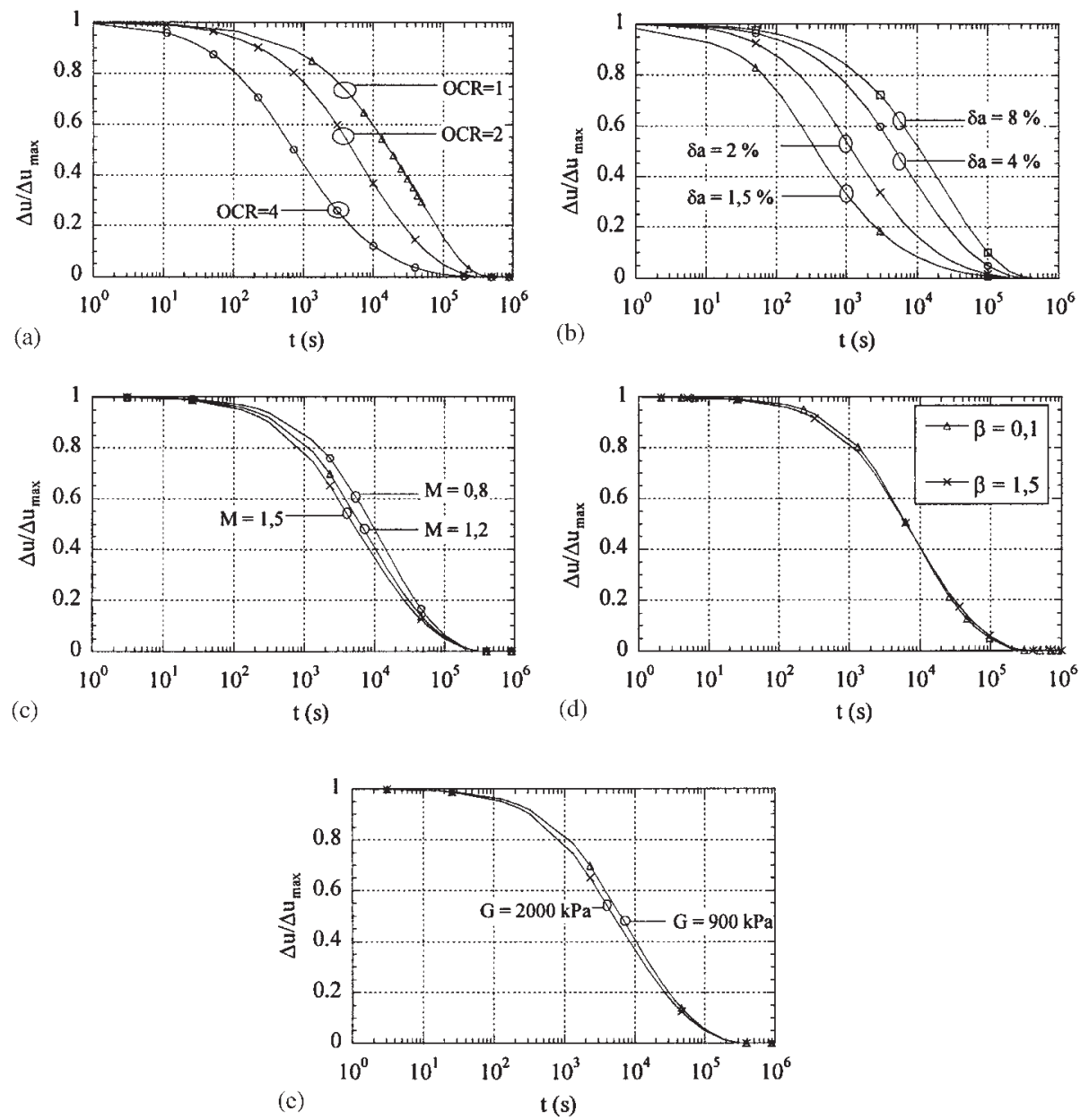

Figure 16. Influence of (a) OCR, (b) $\delta_{a}$, (c) $M$, (d) $\beta$ and (e) $G$ on pore water pressure dissipation curve.

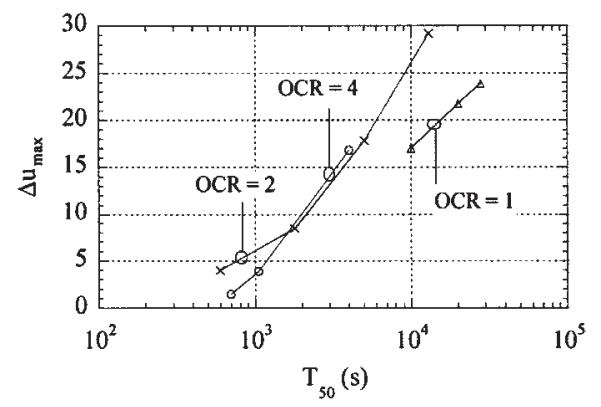

Figure 17. Effect of maximum excess pore pressure on time corresponding to $50 \%$ dissipation during strain holding test. 


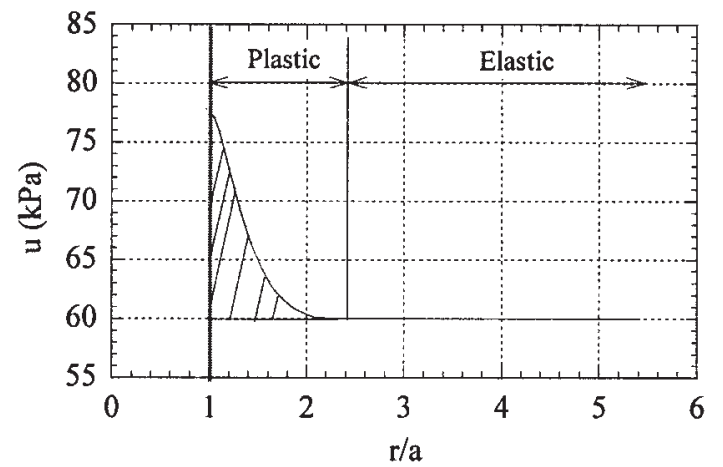

Figure 18. Pore pressure dissipation during strain holding test.

During the dissipation phase, the pore water pressure flow moves from the plastic zone to the elastic zone of the soil. So, the rate of dissipation depends on the maximum excess pore pressure at the cavity wall, on the size of the plastic zone, and also on the distribution of the pore pressure in the plastic zone. This means that the dissipation rate depends on the area under the pore pressure versus radius curve, as illustrated in Figure 18.

\section{IDENTIFICATION PROCEDURE}

Traditionally, we would resolve a mechanical problem by calculating the response ' $R$ ' of a mechanical system ' $S$ ' subjected to actions ' $A$ '. The system ' $S$ ' includes the constitutive model ' $M$ ' and its parameters ' $P$ '. These problems, known as direct problems (Figure 19), could be mathematically expressed in mathematical terms by

$$
R=F(S)
$$

where $F$ represents a functional calculus connecting ' $R$ ' (to be determined) to $S$ (known).

In the inverse problem (as described in this study) one part of the information constituting the system ' $S$ ' is unknown. In our case, the parameters ' $P$ ' of the constitutive model ' $M$ ' are unknown. Therefore, we need complementary information (in the case of this study the response ' $R$ ') in order to rebuild the unknown information (Figure 20).

The inverse problem, as considered in this study, consists of finding a set of parameters ' $P$ ' of the constitutive model ' $M$ ' which would minimize the difference between the experimental data and the results of the calculation obtained from a given set of parameters.

Mathematically, the difference between the observation data and the model prediction is formulated as

$$
L_{n}(S)=\frac{1}{t_{1}-t_{0}} \int\left\|R^{*}(t)-R(S, t)\right\| \mathrm{d} t
$$

where the notation $\|\ldots\|$ represents a norm in the space variable, $t_{1}-t_{0}$ is the time of observation, and $R^{*}(t)-R(S, t)$ is the difference between experimental and numerical data.

In practice, the experimental data are obtained at given times. Thus, the integral in Equation (2) can be replaced in Equation (3) by a sum of the number of measurements $\left(M_{n}\right)$, the 


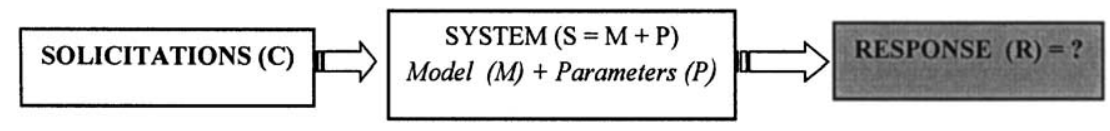

Figure 19. Definition of a direct problem.

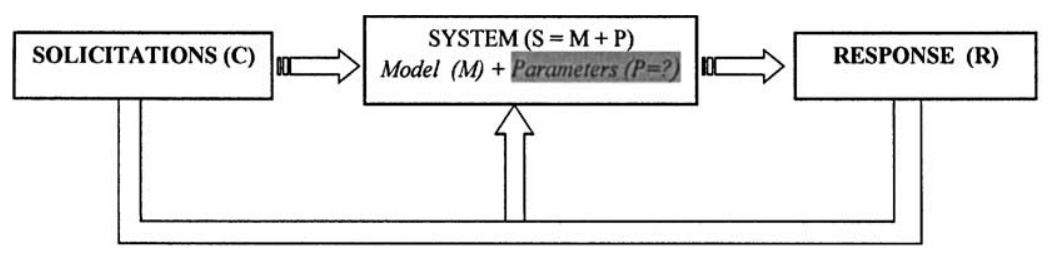

Figure 20. Definition of the inverse problem.

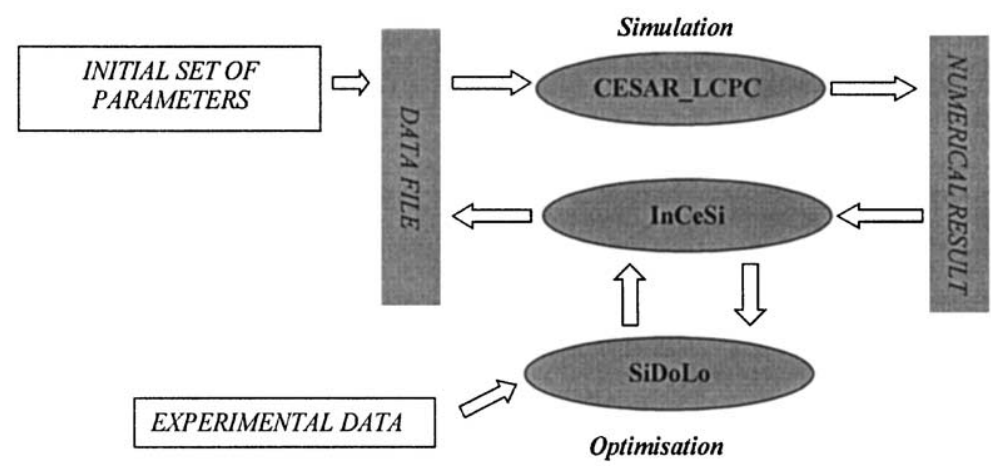

Figure 21. Identification process.

length of observation by the number of measurements $\left(M_{n}\right)$ and a weighting matrix $(D)$ is introduced

$$
L_{n}(P)=\frac{1}{M_{n}} \sum_{i}^{M_{n}}\left[\left(R_{i}^{*}-R_{i}\right)^{\mathrm{T}} D\left(R_{i}^{*}-R_{i}\right)\right]
$$

The matrix $D$ allows us to transform the observable variables into adimensional ones as we divide each of them by the square of the inverse of the error estimation, within the measure of each variable [16].

The coupling of the two codes (CESAR_LCPC and SiDoLo) was performed by the development of an interface code (InCeSi) as presented in Figure 21 [17]. This interface program allows us to perform different tasks such as:

- start the finite element code CESAR_LCPC to simulate the test with a given set of parameters,

- read and process the simulation results inside the optimization tool,

- launch the optimization tool SiDoLo to optimize the set of parameters,

- update the data file for the finite element code. 


\section{VALIDATION ON A NUMERICAL EXAMPLE}

The identification procedure on pressuremeter tests can be realized only with parameters which affect the numerical response in a significant way. A parametric study of the Modified CamClay parameters on the pressuremeter curve was performed by Zentar et al. [17].

A first calculation, called the reference calculation (noted reference in Figures 22(a)-22(c)) was performed with the set of parameter values presented in Table I. In order to examine the effect of each parameter on the calculated pressuremeter curve, we have presented the comparison between the curve obtained with the reference set and the curves obtained by changing the value of one parameter by $50 \%$, all the other parameters being kept equal to the reference value (Figures 22(a)-22(c)).

This study showed that the calculation was greatly affected by the variation of shear modulus $G$, by the preconsolidation pressure $p_{c 0}^{\prime}$, and by the critical state constant $M$, and not affected by the value of $\beta$.

The identification method presented above was thus applied in order to determine $G, M$ and $p_{c 0}^{\prime}$.

By using the reference set of parameters presented in Table I, we performed a numerical simulation of a pressio-triax test. The pressio-triax curve obtained by this simulation was then treated as if it was a result of a real experimental test. Then, by applying the identification procedure on this 'numerical' test, the capability of the method was tested.

Similar validation studies were already presented by Zentar et al. [17], based on pressuremeter test results. The authors showed that the proposed procedure allowed determining simultaneously the parameters pairs $(G, M)$ and $\left(G, p_{c 0}^{\prime}\right)$ from the pressuremeter curve. They demonstrated that the value of the pore water pressure measured at a given point in the soil near
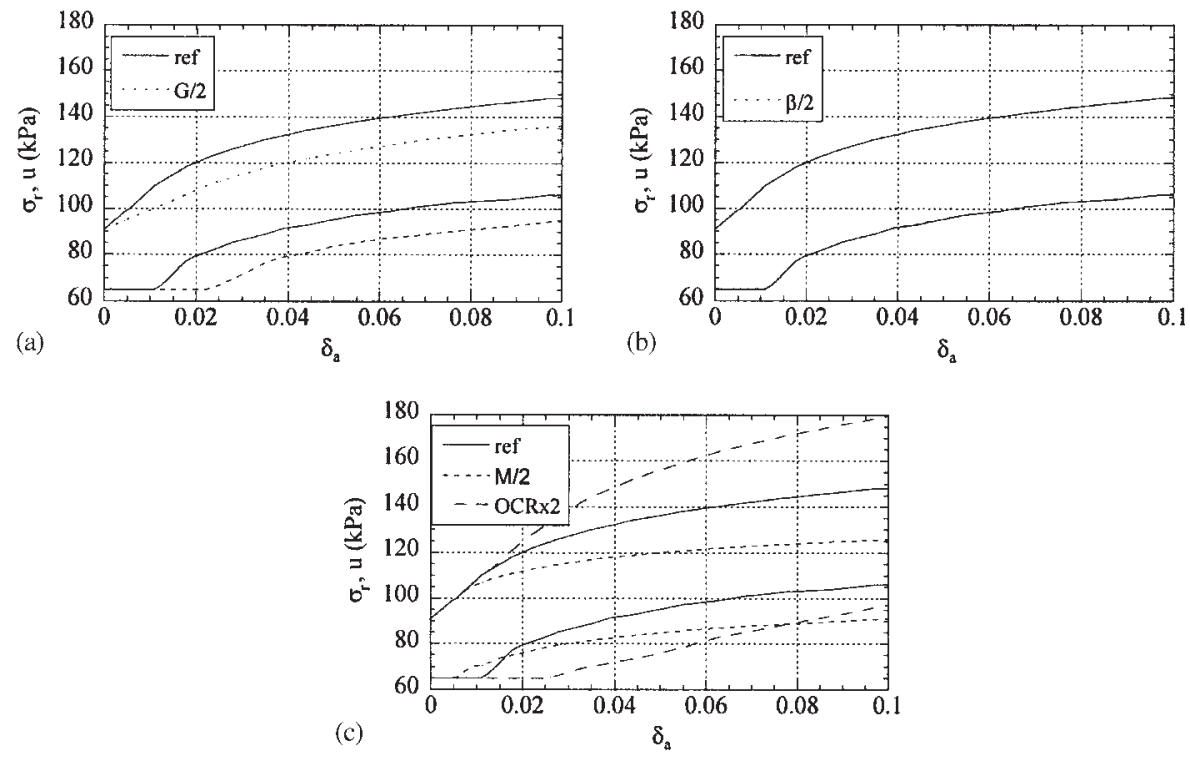

Figure 22. Modified Cam Clay parameter effects on the pressuremeter curve. (a) $G$ effects;

(b) $\beta$ effects; (c) $M$ and $p_{c 0}^{\prime}$ effects. 
Table II. Initial and final values during identification tests for $G, M$ and $p_{c 0}^{\prime}$.

\begin{tabular}{lcccccc}
\hline & Ref. & \multicolumn{2}{c}{ Initial values } & & \multicolumn{2}{c}{ Final values } \\
\cline { 1 - 2 } & & Cal. 1 & Cal. 2 & & Cal. 1 & Cal. 2 \\
\hline$M$ & 1.2 & 0.5 & 1.6 & & 1.2 & 1.2 \\
$p_{c 0}^{\prime}(\mathrm{kPa})$ & 50 & 35 & 70 & & 50 & 50 \\
$G(\mathrm{kPa})$ & 900 & 580 & 1500 & & 900 & 900 \\
\hline
\end{tabular}

Table III. Initial and final values of soil permeability during identification tests.

\begin{tabular}{|c|c|c|c|c|c|}
\hline & \multirow[t]{2}{*}{ Ref. } & \multicolumn{2}{|c|}{ Initial values } & \multicolumn{2}{|c|}{ Final values } \\
\hline & & Cal. 1 & Cal. 2 & Cal. 1 & Cal. 2 \\
\hline$k(\mathrm{~m} / \mathrm{s})$ & $10^{-9}$ & $10^{-6}$ & $10^{-12}$ & $10^{-9}$ & $10^{-9}$ \\
\hline
\end{tabular}

the probe was a necessary complementary information to the pressuremeter curve $\left(p-\delta_{a}\right)$ in order to identify simultaneously the three parameters $G, M$ and $p_{c 0}^{\prime}[13,17]$.

We introduced therefore the pore water pressure curve measured at the cavity wall as complementary information in the optimization procedure. As shown in Table II, starting with two significantly different sets of parameters, the reference set of parameters in each case was correctly identified after a few iterations.

Concerning the identification of the radial permeability from a pressio-triax strain holding test, the same procedure was applied to validate the identification method. First, a pressio-triax test with the reference value presented in Table I was simulated. For a cavity wall strain of $4 \%$ the horizontal displacement of the cavity wall was kept constant. During this stage the pore water pressure dissipated with time as shown in Figure 14. In the identification procedure, the pore water pressure dissipation at the cavity wall $(u)$ with time was used to identify the horizontal permeability of the soil. As shown in Table III, starting the identification procedure with significantly different values of the permeability, the permeability used in the reference calculation is correctly identified after only a few iterations (10-15 iterations).

Knowing that the soil permeability has an effect on the pressuremeter curve and on the pore water curve, and that the mechanical parameters have an influence on the dissipation curve during a strain holding test, we constructed the identification procedure used to identify both the mechanical and the hydraulic parameters from pressuremeter with strain holding test as follows:

- First, a fixed value of the permeability $k$ is chosen and the mechanical parameters are determined from pressuremeter and pore water pressure curves by use of the identification procedure described above (set of parameters $P_{0}$ ).

- The set $P_{0}$ is then fixed and a value of the permeability $\left(k_{1}\right)$ is computed from the strain holding test.

- Taking into account this new value of the permeability, another set of mechanical parameters $P_{1}$ is computed as in stage 1 .

- Then, this set $P_{1}$ is used to determine another value of permeability $k_{2}$. 
- Few iterations are realized until the mechanical and hydraulical parameter values allow a correct representation of both the pressuremeter curve and the pore water pressure curve during the cavity loading and the pore pressure dissipation curve during the strain holding test.

\section{APPLICATION ON PRESSIO-TRIAX TEST RESULTS}

\subsection{Pressio-triax equipment}

In order to quantify experimentally the permeability influence on test results, the numerical study presented above has shown that it is necessary to know the pore water pressure development during a pressuremeter test. Thus, special laboratory equipment was developed to study a pressuremeter test in tightly controlled laboratory conditions. A special aspect of this equipment is its ability to measure the pore water pressure evolution at the cavity wall during a pressuremeter test $[13,9]$.

The apparatus, called pressio-triax, is essentially a modified triaxial cell and a minipressuremeter probe set in the middle of the specimen and connected to a GDS jack. A schematic cross-section of the assembled cell apparatus is presented in Figure 23.

The modified cell allows us to test specimen of $105 \mathrm{~mm}$ in height and a cross-section of $38.48 \mathrm{~cm}^{2}$. The height to diameter ratio is 1.5 . During the sample preparation, the minipressuremeter probe of $13 \mathrm{~mm}$ in diameter is introduced in the centreline of the specimen by way of a special device, which reproduces the self-boring pressuremeter device [12]. The ratio between the diameter of the specimen and the diameter of the mini-pressuremeter probe is 5.38, and corresponds to the geometry used in the numerical simulations presented above. The equipment allows pore water pressure measurement at the cavity wall. A displacement transducer is fixed on the loading axis of the modified cell. In order to stamp out the deformations due to the whole setting, we performed a calibration test before each series of

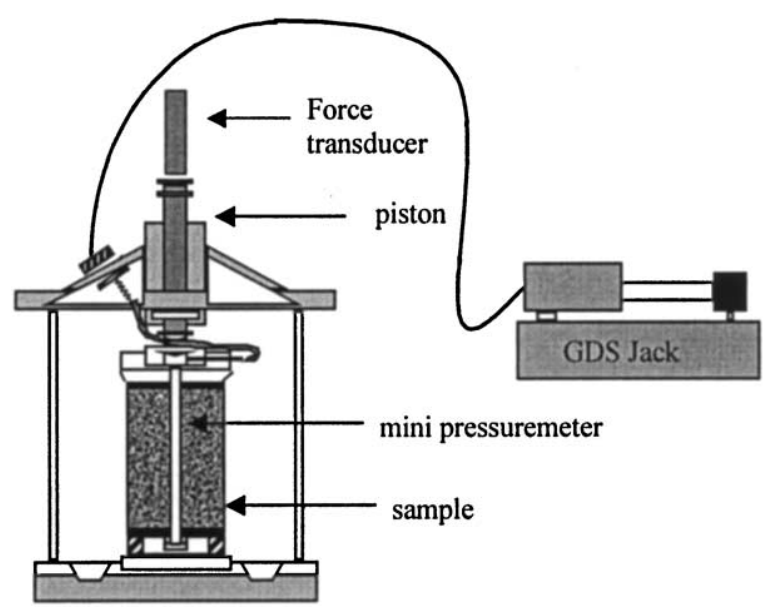

Figure 23. Pressio triax apparatus. 


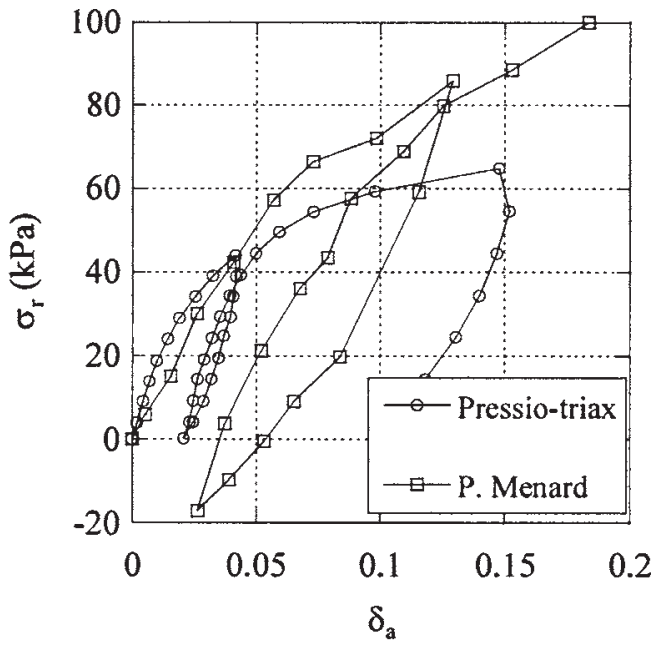

Figure 24. Comparison between pressuremeter curves from Menard pressuremeter test and pressio triax test [12].

tests. We were therefore able to determine the real height of the specimen with an accuracy of $0.01 \mathrm{~mm}$. A force transducer of $250 \mathrm{~N}$ capacity is mounted as shown in Figure 23. The measurement accuracy of the transducer is $0.5 \mathrm{~N}$; the vertical stress can thus be defined with an accuracy of $1 \mathrm{kPa}$.

To ensure the probe expansion, the mini-pressuremeter is connected to a GDS jack. This jack makes it possible to carry out a controlled rate of strain test or a controlled rate of stress test. The measurement accuracy of the pressure transducer is $1 \mathrm{kPa}$; the volume changes in the probe are measured with an accuracy of $1 \mathrm{~mm}^{3}$.

In the numerical simulation of the pressio-triax test, the real geometry of the specimen has to be taken into account. The influence of the ratio $b / a$ on the pressuremeter curve was presented by Zentar [12].

Assuming an elastic perfectly plastic model, the difference between pressuremeter curve and pressio-triax curve can be expressed as follows:

$$
\Delta \sigma_{r}=\delta_{a} 2 G \frac{a^{2}}{b^{2}}
$$

Figure 24 presents a comparison between the result of a Menard pressuremeter test performed on the site of Saint-Herblain, and a pressio-triax test performed in laboratory on the SaintHerblain clay.

For Saint-Herblain clay, the shear modulus is typically $1500 \mathrm{kPa}$. The difference between the classical pressuremeter curve and the pressio-triax curve can be calculated by using expression (4). Knowing that the radii $a$ is $6.5 \mathrm{~mm}$ and $b$ is $35 \mathrm{~mm}$, for a cavity deformation $\delta_{a}$ of $10 \%$, the difference is $10 \mathrm{kPa}$. This difference is in good agreement with the one observed in Figure 24 between pressuremeter and pressio-triax curves.

In the following, the procedure used to identify soil parameters takes into account the real geometry of the pressio-triax test. 


\subsection{Parameters identification}

The studied site, named Saint-Herblain, is situated in the Loire Paleolithic period. Modern river clayey alluvium deposits constitute this site. The clay is characterized by a high plasticity index and is slightly or moderately organic and overconsolidated at the surface. The samples of soil used for this study were taken at a depth of 5.5-6.5 m.

At the depth of our study, five pressio-triax tests were realized with different strain rate varying between $1.5 \times 10^{4}$ and $6 \times 10^{7} \mathrm{~s}^{1}$ (corresponding, respectively, to the probe inflation rate of 1 and $250 \mathrm{~mm}^{3} / \mathrm{min}$ ).

For each test, after settling the sample, the specimen was consolidated by the use of a single step procedure. At this stage, during the whole time of consolidation, we maintained an equal pressure within the cell and within the pressuremeter probe.

To insure full saturation during consolidation, a back pressure was also applied. Before starting the tests, first the drainage valves were closed to maintain overall undrained conditions during cavity expansion and the top plate was rigidly fixed to insure a plane strain condition.

The displacements of the inner cavity wall $\left(d_{a}\right)$ of the specimen were deduced from the volume change of the mini-pressuremeter probe assuming a cylindrical expansion of the probe.

The consolidation phase was realized under the initial state of stress defined in Table IV.

During the pressio-triax test, strain holding tests were performed at two different cavity strain levels: 1.5 and $3.5 \%$. After each pressio-triax test, the specimens were reconsolidated under their initial state of stress. Then, a classical triaxial test was performed in order to measure the undrained shear strength (noted $c_{\mathrm{ut}}$ ) for each specimen.

The physical and mechanical characteristics, and the strain rate used for each test are summarized in Table V.

We can see from Table $\mathrm{V}$ that both physical characteristics (water content and unit weight) and shear strength values were almost constant from one specimen to another. So, we can consider that all specimens were similar in term of physical and mechanical characteristics.

Table IV. Initial state of stress used for each sample.

\begin{tabular}{lcccc}
\hline Test & $p_{0}\left(=\sigma_{\mathrm{h} 0}\right)$ & $\begin{array}{c}\sigma_{\mathrm{v} 0} \\
(\mathrm{kPa})\end{array}$ & $u_{0}$ & $p_{0}^{\prime}\left(=\sigma_{\mathrm{h} 0}^{\prime}\right)$ \\
\hline TA & 71 & 85 & 56.5 & 19.2 \\
TB & 73 & 85 & 55.0 & 22.0 \\
TC & 75 & 85 & 55.0 & 23.3 \\
TD & 74 & 85 & 55.6 & 22.1 \\
\hline
\end{tabular}

Table V. Physical and mechanical characteristics of Saint Herblain clay samples.

\begin{tabular}{lcccc}
\hline Specimen & $\begin{array}{c}\text { Water content } \\
(\%)\end{array}$ & $\begin{array}{c}\text { Unit weight } \\
\left(\mathrm{kN} / \mathrm{m}^{3}\right)\end{array}$ & $\begin{array}{c}\text { Strain rate } \\
\left(\mathrm{s}^{-1}\right)\end{array}$ & $\begin{array}{c}c_{\text {ut }} \text { (deduced } \\
\text { from triaxial test }) \\
(\mathrm{kPa})\end{array}$ \\
\hline TA & 97 & 13.96 & $3 \times 10^{-5}$ & 20.5 \\
TB & 96 & 14.21 & $6 \times 10^{-7}$ & 19 \\
TC & 85 & 14.22 & $1.5 \times 10^{-4}$ & 20 \\
TD & 85 & 14.21 & $6 \times 10^{-6}$ & 20.5 \\
\hline
\end{tabular}



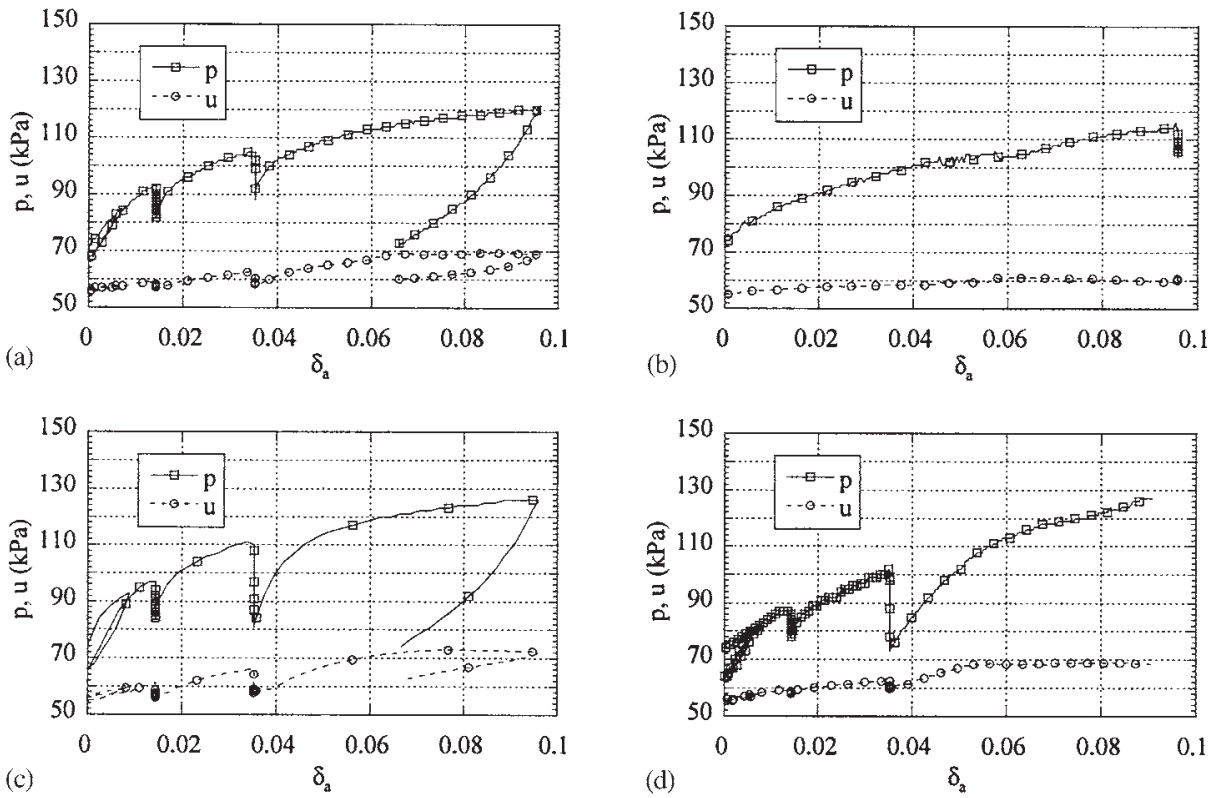

Figure 25. Pressure and pore water pressure at the cavity wall during pressio triax tests. (a) Test TA $\left(\dot{\delta}_{a}=3 \times 10^{-5} \mathrm{~s}^{-1} ; 50 \mathrm{~mm}^{3} / \mathrm{min}\right) ;(\mathrm{b})$ test TB $\left(\dot{\delta}_{a}=6 \times 10^{-7} \mathrm{~s}^{-1} ; 1 \mathrm{~mm}^{3} / \mathrm{min}\right) ;(\mathrm{c})$ test TC $\left(\dot{\delta}_{a}=1.5 \times\right.$ $\left.10^{-4} \mathrm{~s}^{-1} ; 250 \mathrm{~mm}^{3} / \mathrm{min}\right) ;(\mathrm{d})$ test TD $\left(\dot{\delta}_{a}=6 \times 10^{-6} \mathrm{~s}^{-1} ; 10 \mathrm{~mm}^{3} / \mathrm{min}\right)$.

The pressio-triax curve and the pore pressure curve obtained from each test are shown in Figure 25. For the test TB, with a strain rate of $6 \times 10^{7} \mathrm{~s}^{1}$ (volume change rate in the probe equal to $1 \mathrm{~mm}^{3} / \mathrm{min}$ ), very small changes in the pore pressure were generated at the cavity wall. So, no strain holding test stage was performed during this test. For the other tests, considering the small values of the generated pressure at the cavity wall at the beginning of the first strain holding test $\left(\delta_{a}=1.5 \%\right)$, only the second strain holding test stage $\left(\delta_{a}=3.5 \%\right)$ was used to deduce soil radial permeability.

The method described Section 4.4 was used here to derive the parameters $G, M, p_{c 0}^{\prime}$ and $k$ from test TA, TC and TD.

In Figures 26 and 27, the experimental test (exp) and the numerical simulation (sim) results are reported for tests TA and TC. The figures show an excellent agreement between experimental and numerical curves for the loading stage (Figure 26(a) and 27(a)) and also during the strain holding test (Figure 26(b) and 27(b)) for the pore pressure dissipation.

The values obtained after the optimization procedure are reported in Table VI. The value of the preconsolidation pressure $p_{c 0}^{\prime}$ is close to the one obtained from one dimensional consolidation test (40-50 $\mathrm{kPa}$ for this depth) and the value of the critical state parameter is close to the one obtained from classical undrained triaxial shearing tests $(M=1.25)$.

The value of the permeability and the strain rate of each test can be used to determine the conditions of drainage during the pressio-triax test, as shown in Section 2.3. Figure 12, presented in that section, can be transformed into the one presented in Figure 28. In this figure, the points representing each test (strain rate and permeability) allow us to classify the drainage conditions of the tests. 

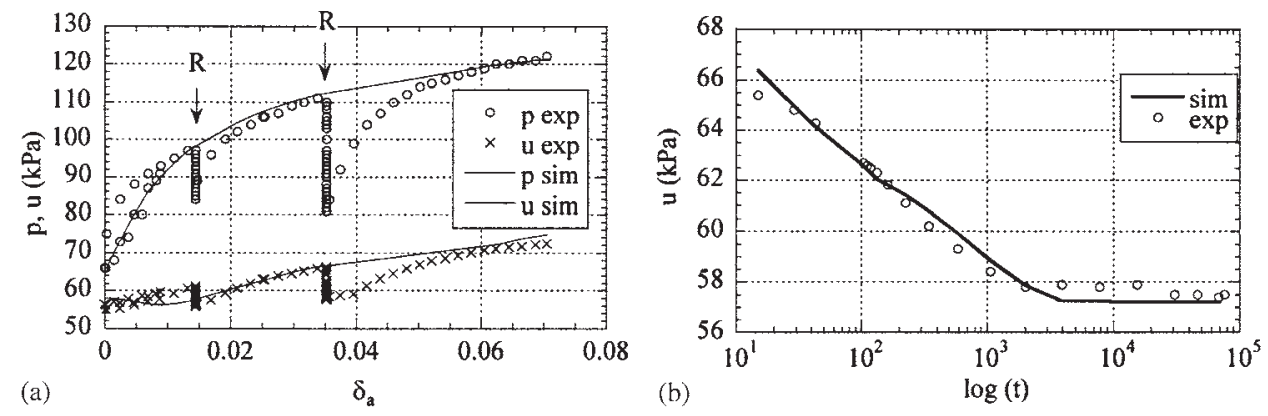

Figure 26. Comparison between experiment and simulation of test TC.
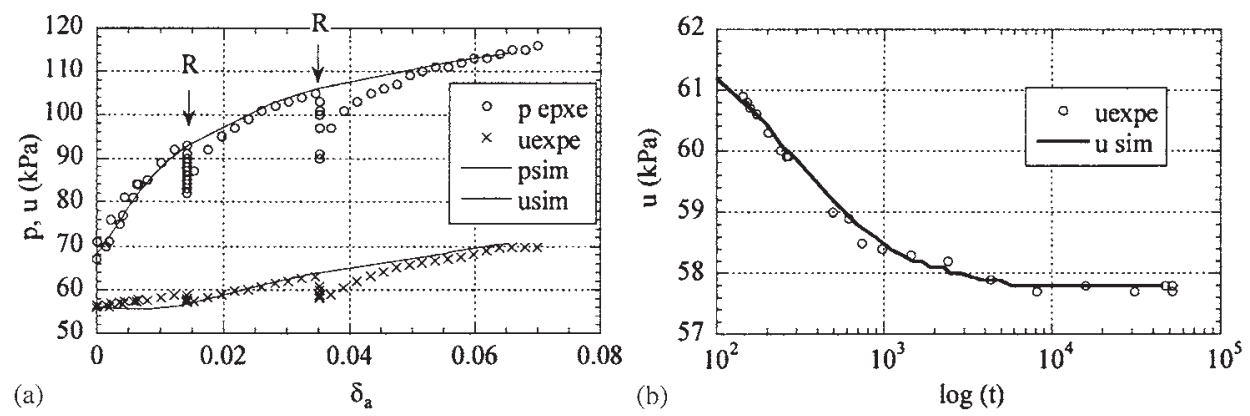

Figure 27. Comparison between experiment and simulation of test TA.

Table VI. Results of exploiting strain holding tests.

\begin{tabular}{lcccc}
\hline Test & $\begin{array}{c}G \\
(\mathrm{kPa})\end{array}$ & $M$ & $\begin{array}{c}p_{c 0}^{\prime} \\
(\mathrm{kPa})\end{array}$ & $\begin{array}{c}k \\
(\mathrm{~m} / \mathrm{s})\end{array}$ \\
\hline TA & 1120 & 1.20 & 48 & $1.4 \times 10^{-7}$ \\
TC & 1690 & 1.21 & 50 & $3.7 \times 10^{-8}$ \\
TD & 1620 & 1.22 & 37 & $1.8 \times 10^{-7}$ \\
\hline
\end{tabular}

We can note from this figure that only the tests TC occurred in totally undrained condition. For the other test (tests TA and TC), with a lower strain rate, the condition was partially drained, type B (the partially drained type B condition corresponds to the case where the permeability has an influence on the pore pressure generation, but does not affect the total stress evolution).

The comparison between the excess pore pressure and the total pressure at the cavity wall for each test (Figure 29) shows the influence of the drainage condition on the test results. In particular, for tests TA and TD, which were performed with the same drainage conditions (Figure 28), we can see that the values of the generated excess pore pressure are similar. Concerning the total pressure at the cavity wall, the drainage conditions have no influence on the pressuremeter curves obtained from tests TA, TC and TD. This result is in agreement with the drainage conditions determined in Figure 28. Indeed, these tests occurred in undrained (TC) 


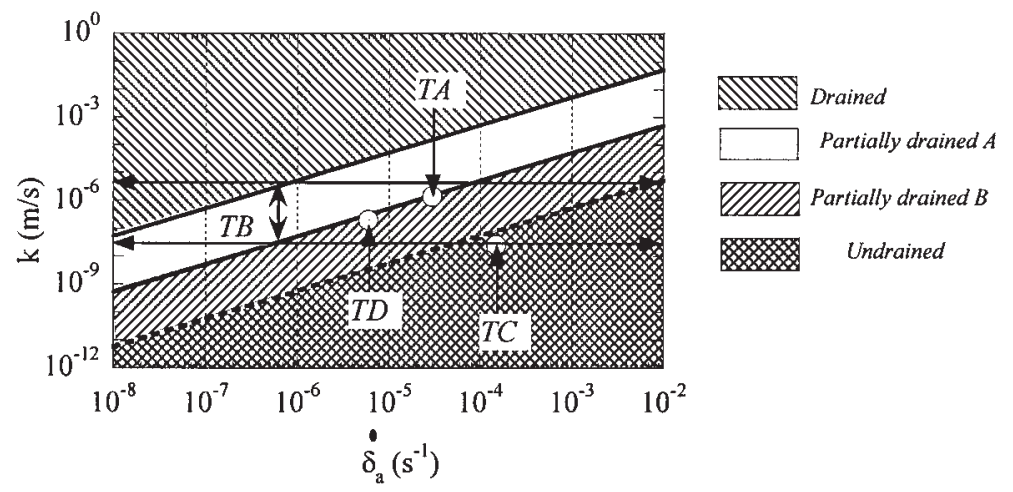

Figure 28. Drainage conditions during a pressio triax test regarding the permeability and the strain rate.
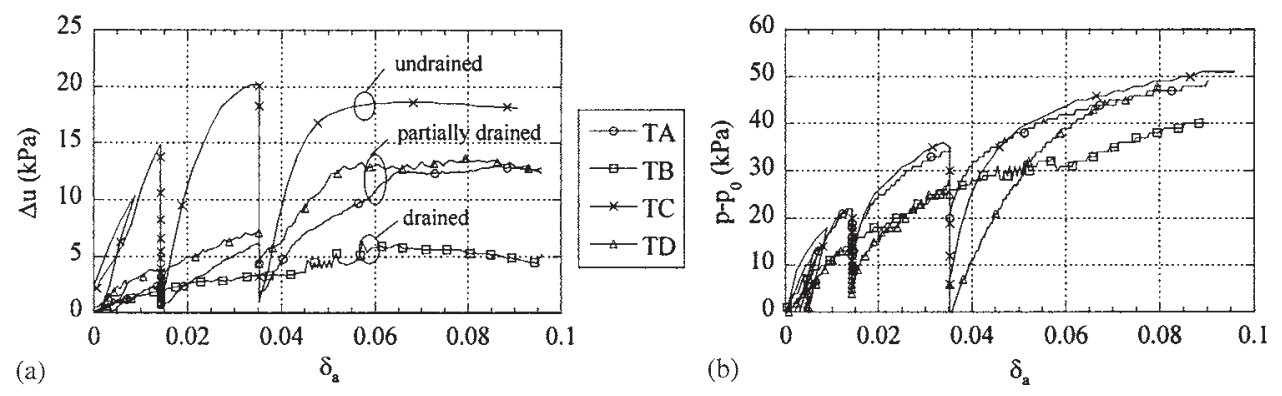

Figure 29. Excess pore water pressure generated during pressio triax tests.

Table VII. Parameters $G$ and $p_{c 0}^{\prime}$ obtained by back analysis from test TB $(M=1.20)$.

\begin{tabular}{lcc}
\hline $\begin{array}{l}k \\
(\mathrm{~m} / \mathrm{s})\end{array}$ & $\begin{array}{c}G \\
(\mathrm{kPa})\end{array}$ & $\begin{array}{c}p_{c 0}^{\prime} \\
(\mathrm{kPa})\end{array}$ \\
\hline $1 \times 10^{-8}$ & 1050 & 28.5 \\
$1 \times 10^{-7}$ & 1050 & 31.5 \\
$1 \times 10^{-6}$ & 1050 & 33.5 \\
\hline
\end{tabular}

and partially drained type B (TA and TD) conditions. However, the total pressure in test B is significantly smaller than the total pressure reached during the other tests, which is in agreement with the fact that this test occurred in partially drained type A conditions.

The back analysis procedure was applied only on the pressuremeter curve obtained from test TB taking into account a permeability value of $1 \times 10^{6}, 1 \times 10^{7}$ and $1 \times 10^{8} \mathrm{~m} / \mathrm{s}$. Without the pore pressure curve, only one of the parameters $M$ and $p_{c 0}^{\prime}$ could be determined.

Considering that the value of $M$ obtained from the other tests vary between 1.20 and 1.22 , we chose to fix $M=1.20$ and to run the optimization procedure to determine $G$ and $p_{c 0}^{\prime}$. In Table VII, the results show that the shear modulus kept constant value, but that the preconsolidation pressure $p_{c 0}^{\prime}$ increased with the permeability value. Considering the value of $p_{c 0}^{\prime}$ obtained from the other tests (between 37 and $50 \mathrm{kPa}$ ), a value of $33.5 \mathrm{kPa}$ appears more 
reliable than the smaller values. So, we can assume that the permeability of test TB is about $1 \times 10^{6} \mathrm{~m} / \mathrm{s}$, which leads to test conditions situated between partially drained type A and totally drained conditions. This is in agreement with our previous remarks. However, the reliability of the obtained parameters can be questioned in this case and need to be reconsidered more carefully if not completely disregarded.

The undrained shear strength values derived from the method described by Gibson and Anderson are 22, 19, 26, $22 \mathrm{kPa}$ for, respectively, tests TA, TB, TC and TD. We can note that for test $\mathrm{TB}$, which occurred in almost drained condition, the $c_{\mathrm{u}}$ value is significantly smaller than those obtained from the other tests. As shown in Section 2.3, partial drainage in soil during pressuremeter test can affect the value of the shear strength according to Gibson and Anderson [4] method. We showed that the drained condition modifies the $c_{\mathrm{u}}$ value by $25 \%$. So, if we consider that test B occurred in drained conditions, the corrected $c_{\mathrm{u}}$ value is $25 \mathrm{kPa}$. This value is close to those obtained from other tests, especially from the one obtained from test TC which occurred in undrained conditions.

As far as permeability is concerned, the values obtained by the proposed method vary from $1.4 \times 10^{7}$ to $3.7 \times 10^{8} \mathrm{~m} / \mathrm{s}$ for the different specimens. This difference may be due to the vegetable remains, which help the radial drainage, and therefore can increase the value of the horizontal permeability. Knowing that the vertical permeability derived from a classical method is typically $1 \times 10^{9} \mathrm{~m} / \mathrm{s}$ for the Saint-Herblain clay, the permeability ratio $k_{\mathrm{h}} / k_{\mathrm{v}}$ varies between 30 and 100. This ratio is common to alluvial deposits such as in the case of this soft clay.

\section{CONCLUSION}

In this study, our aim was to prove the importance of radial permeability on a pressuremeter test result realized on natural soft clay.

First, a numerical study was undertaken by using a finite element code CESAR_LCPC, and by modelling the behaviour of the soil with the modified Cam-Clay model. These studies highlighted the influence of the radial permeability on the stress path and therefore on the pressuremeter curve. It was shown that drainage conditions strongly influence the value of the mechanical characteristics (especially the undrained shear strength) derived from the pressuremeter curve obtained by conventional methods. So, a diagram was built in order to determine the drainage conditions, given the permeability and the strain rate of each test.

Secondly, numerical analyses of a strain holding test stage during a pressuremeter test were performed. We showed that permeability has an important effect on the pore pressure dissipation during this kind of test. We also showed that other parameters (especially the overconsolidation ratio and the slope $M$ of the critical state line) have an effect on the dissipation rate during this test.

Finally, an inverse method was developed to determine the parameters of the modified CamClay model from pressio-triax tests. Numerical tests were at first performed in order to validate this procedure. Knowing the pressuremeter curve and the pore pressure evolution at a given point near the probe, we showed that the identification procedure was able to produce simultaneously the three parameters which have a significant influence on a numerical simulation of a pressuremeter test (shear modulus $G$, critical state parameter $M$ and preconsolidation pressure $p_{c 0}^{\prime}$ ). Regarding the permeability influence on the strain holding test, we also used this identification procedure to identify soil permeability from pore water pressure 
dissipation during this test. A general procedure to identify simultaneously the mechanical parameters and the permeability value is proposed: the mechanical parameters are identified on the pressuremeter curve, and then, taking the optimized set of parameters obtained, the permeability is derived from the pore pressure dissipation curve during a strain holding test. Few iterations need to be realized on the two optimization procedures in order to obtain both mechanical parameters and permeability.

A new experimental equipment for simulating a pressuremeter test in the laboratory was then described. This equipment called pressio-triax can also measure the pore pressure measurement at the cavity wall during the expansion test. The identification procedure presented above was applied on pressio-triax tests with strain holding test stages realized on Saint-Herblain clay. We could derive the parameters $G, M, p_{c 0}^{\prime}$ and the permeability $k$ for this clay. However, in order to obtain reliable results, the drainage conditions of the tests must be carefully taken into account. The comparison between the parameters obtained by this procedure and those obtained from classical laboratory tests showed the ability of the proposed procedure to identify correctly the clay parameters.

\section{REFERENCES}

1. Menard L. Pressiometre. Brevet Français d'invention, No. 1.117.983, 1955.

2. Baguelin F, Jezequel J, Le Mee E, Le Mehaute A. Expansion of cylindrical probe in cohesive soils. Journal of Soil Mechanics and Foundation Division ASCE 1972; 98(SM11):1129 1142.

3. Wroth CP, Hugues JMO. An instrument for the in situ measurement of the properties of soft clay. In Proceedings of the Eighth Conference on Soil Mechanics and Foundation Engineering, Moscow, 1972; 487494.

4. Gibson RE, Anderson WF. In situ measurement of soils properties with the pressuremeter. Civil Engineering and Public Works Reviews 1961; 56(658):615 618.

5. Palmer AC. Undrained plane strain expansion of a cylindrical cavity in clay, a simple interpretation of the pressuremeter test. Geotechnique 1972; 22(3):451 457.

6. Vaid YP, Campanella RG. Time dependent behavior of undisturbed clay. Journal of Geotechnology Engineering, ASCE 1977; 103(7):693 709 .

7. Hanzawa H, Tanakaz H. Numerical undrained strength of clay in the normally consolidated state and in the field. Soils and Foundation 1992; 32(1):132 148.

8. Sheahan TC, Ladd CC, Germaine JT. Rate dependent undrained shear behavior of saturated clay. Journal of Geotechnology Engineering, ASCE 1996; 122(2):99 108.

9. Rangeard D, Zentar R, Moulin G, Hicher PY. Strain rate effect on pressuremeter test result on soft clay. In Proceedings of the International Conference on Soil Properties and Case Histories, Bali, 2001.

10. Randolph MF, Wroth CP. An analytical solution for the consolidation around a driven pile. International Journal for Numerical and Analytical Methods in Geomechanics 1979; 3(3):217 230.

11. Fiovarante V, Jamiolkowski M, Lancellotta R. An analysis of pressuremeter holding tests. Geotechnique 1994; 44(2):227 238.

12. Zentar R. Analyse inverse des essais pressiométriques, application à l'argile de Saint Herblain. Thèse de doctorat, Ecole Centrale de Nantes, 1999.

13. Zentar R, Moulin G, Hicher PY. Numerical analysis of pressuremeter test in soil. In Proceedings of the Fourth European Conference on Numerical Methods in Geotechnical Engineering, Udine Italie, 1998; 593600.

14. Bahar R. Analyse numerique de l'essai pressiometrique: application a l'identification de parametres de comportement des sols. These de doctorat, Ecole Centrale de Lyon, 1992.

15. Roscoe KH, Burland JB. On the generalised strain stress behavior of 'wet' clay. Engineering Plasticity. Cambridge University Press, Cambridge, 1968; 535609.

16. Pilvin P, Cailletaud G. Identification and inverse problems related to material behavior. In Inverse Problems in Engineering Mechanics, Rotterdam, Balkema, 1994; 7986.

17. Zentar R, Hicher PY, Moulin G. Identification of soil parameters by inverse analysis. Computers and Geotechnics 2001; 28(2):129 144. 